\title{
A study on relationship between income, health and family relationship and happiness
}

\author{
Mahmoud Moradi $^{\mathbf{a}^{*}}$, Mehdi Meshki ${ }^{\mathrm{b}}$ and Amaneh Jabbarzade ${ }^{\mathrm{c}}$
}

${ }^{a}$ Assist.Prof. \& Faculty Member, Department of Management, University of Guilan, Rasht, Iran

${ }^{b}$ Assist.Prof. \& Faculty Member, Department of Accounting, Payame Noor University, Rasht, Iran

${ }^{c}$ M.A. Student, Department of Management (MBA), University of Guilan (International Pardis), Rasht, Iran

\section{H R O N I C L E A B S T R A C T}

Article history:

Received October 27, 2012

Received in revised format

29 January 2013

Accepted 18 February 2013

Available online

February 212013

Keywords:

Subjective happiness scale

Satisfaction with life scale

Happiness

\begin{abstract}
This paper presents a social work study on relationship between exogenous components including monthly income, family relationship and physical health and endogenous variables including subjective happiness scale (SHS), satisfaction with life scale (SWLS) and happiness. The proposed study designs a questionnaire and distributes it among 254 employees of private banks in city of Tehran, Iran during the year of 2012. Cronbach's Alpha and Dillon-Goldstein's Rho both are well above 0.70, for SHS and SWLS and Eigenvalue for both components were greater than one. T-student values for all components were greater than 1.96, which means they are meaningful. Mean Communalities (Ave) calculated for both Latent Variables were greater than 0.50 . The results of investigating various questions of the survey indicate that while healthcare is the most important factor on happiness, there is a positive and meaningful relationship between income and family relationships and happiness.
\end{abstract}

\section{Introduction}

Happiness is the main concern in any society and there are always different perceptions on what it means and how different factors influence happiness (Lyubomirsky \& Lepper, 1999). In fact, the last decade has witnessed an explosion of interest in the scientific study of happiness. Blanchflower and Oswald (2004), for instance, investigated happiness in the United States and Great Britain. Paul and Guilbert (2013) performed a study to find out whether the theories of adaptation and social comparison could explain the income-happiness puzzle in Australia. Their investigation provided no support for the adaptation impact on happiness. However, they reported strong support for the theory of social comparison as an explanation for the happiness paradox. In other words, an increase in peer group income could hurt the poor more than the rich, implying that a redistribution of income was likely to enhance the overall wellbeing of society.

\footnotetext{
Corresponding author. Tel: +98-911-2828735

E-mail: m.moradi@guilan.ac.ir (M. Moradi)

(c) 2013 Growing Science Ltd. All rights reserved. doi: 10.5267/j.msl.2013.02.017
} 
According Kahneman and Deaton (2010), there is a growing interest to distinguish two aspects of subjective well-being. They raised a question of whether money buys happiness by analyzing more than 450,000 responses to the Gallup-Healthways Well-Being Index, a daily survey of 1,000 US residents conducted by the Gallup Organization. They reported that emotional well-being and life evaluation were correlated, differently. Income and education were more closely associated with life evaluation, but health, care giving, loneliness, and smoking were relatively stronger predictors of daily emotions. They concluded that "high income buys life satisfaction but not happiness, and that low income is associated both with low life evaluation and low emotional well-being”.

Oshio and Kobayashi (2010) investigated how regional inequality was associated with perceived happiness and self-rated health at an individual level by implementing micro-data from nationwide surveys in Japan. They reported that individuals who live in areas of high inequality would more likely consider themselves as both unhappy and unhealthy, even after controlling for different individual and regional characteristics and taking into account the correlation between the two subjective outcomes. In their survey, gender, age, educational attainment, income, occupational status, and political views modified the associations of regional inequality with the subjective assessments of happiness and health.

According to McBride (2010), economists reported that happiness increases in income but decreased in income aspirations, and this work examined how aspirations form and adapt over time. The study reported that expectations and social comparisons significantly could influence reported satisfaction and they findings supported an aspirations-based theory of happiness. Zelenski et al. (2008) combined longitudinal prospective and experience sampling techniques to test the relationship between happiness and self-reported productivity among Directors hired in the public and private sectors. Among the happiness indicators investigated (job satisfaction, quality of work life, life satisfaction, positive affect, and negative affect) positive affect was most strongly, but not exclusively, tied to productivity at both the state and trait levels.

Pouwels et al. (2008) performed an empirical analysis and studied whether the effect of income on happiness tends to be underestimated by ignoring the fact that income had to be earned. They confirmed this by using the German Socio-Economic Panel. Kafetsios (2006) examined the relationships between structural and functional indicators of supportive relations and well-being in Greece at different levels. They reported that structural and functional aspects of social support in Greece might not have the same palliative impact as usually believed in the international literature.

Di Tella and MacCulloch (2006) demonstrated how the differences in US and European institutions could arise in a normative model. They concentrated on the labor market and the government's decision to set unemployment benefits in response to an unemployment shock. They reported that when an adverse shock occurs, benefits should be increased most when the adverse incentive influences of benefits are relatively big.

Graham (2008) reviewed the happiness-health relationship from an economics perspective, highlighting the impact of adaptation. Many studies on unhappiness and obesity indicate that norms and stigma vary a great deal across countries and cohorts, mediating the related well-being expenses. Better understanding this variance and its impacts on incentives for addressing the condition was important to policy design. Bruni (2004) stated that in the leaders of the Cambridge tradition of economics the issue of the 'happiness transformation problem', i.e. how wealth becomes well-being, was a central point.

\section{The proposed study}

The proposed study designs a questionnaire and distributes it among 254 employees of private banks in city of Tehran, Iran during the year of 2012. In our survey, $46.9 \%$ of the participants were female and $53.1 \%$ of them were male. In terms of educational background, $7.5 \%$ of the participants only finished high school, $33.5 \%$ of them hold bachelor of sciences, $43.3 \%$ of the participants had master degree and the remaining $15.7 \%$ of the participants hold PhD degree. In terms of age perspectives, 
only one person aged less than 20 years, 37\% of the participants were between 20 to 30 years of age, $43.3 \%$ of them were $30-40$ years old, $13.4 \%$ of the participants were between 40 to 50 years and only $5.9 \%$ of them were older than 50 years. Finally, 33.5\% of the participants were single and $60.2 \%$ of them had no children. Cronbach's Alpha and Dillon-Goldstein's Rho both are well above 0.70, for feeling happiness and feeling satisfied from life and Eigenvalue for both components were greater than one. T-student values for all components were greater than 1.96, which means they are meaningful. Mean Communalities (Ave) calculated for both Latent Variables were greater than 0.50. In addition, all Cross-Loadings confirmed the validity of the results and they are demonstrated in Table 1. Here, satisfaction with life scale (SWLS) is the latent variable with five components and subjective happiness scale (SHS) is the manifest variable with four components.

\section{Table 1}

The results of Cross-loadings and correlations

\begin{tabular}{|c|c|c|c|c|c|c|}
\hline \multirow{2}{*}{ Latent variable } & \multicolumn{3}{|c|}{ Cross-loadings } & \multicolumn{3}{|c|}{ Correlations (Dimension) } \\
\hline & Manifest variables & SHS & SWLS & Loadings & Standard error & Critical ratio (CR) \\
\hline \multirow{4}{*}{$\stackrel{\mathscr{I}}{\stackrel{I}{\sim}}$} & SHS1 & 0.843 & 0.506 & 0.843 & 0.027 & 31.161 \\
\hline & SHS2 & 0.846 & 0.548 & 0.846 & 0.034 & 24.898 \\
\hline & SHS3 & 0.836 & 0.524 & 0.836 & 0.025 & 32.871 \\
\hline & SHS4 & 0.758 & 0.395 & 0.758 & 0.051 & 14.863 \\
\hline \multirow{5}{*}{$\sum_{\infty}^{\infty}$} & SWLS1 & 0.549 & 0.884 & 0.884 & 0.019 & 45.558 \\
\hline & SWLS2 & 0.531 & 0.822 & 0.822 & 0.030 & 27.690 \\
\hline & SWLS3 & 0.545 & 0.770 & 0.770 & 0.031 & 24.568 \\
\hline & SWLS4 & 0.455 & 0.829 & 0.829 & 0.024 & 35.072 \\
\hline & SWLS5 & 0.379 & 0.747 & 0.747 & 0.038 & 19.857 \\
\hline \multicolumn{2}{|c|}{ AVE } & 0.675 & 0.659 & \multicolumn{3}{|c|}{ Critical value $=0.50$} \\
\hline \multicolumn{2}{|c|}{ Cronbach's alpha } & 0.831 & 0.865 & \multicolumn{3}{|c|}{ Critical value $=0.70$} \\
\hline \multicolumn{2}{|c|}{ D.G. rho } & 0.888 & 0.904 & \multicolumn{3}{|c|}{ Critical value $=0.70$} \\
\hline \multicolumn{2}{|c|}{ Eigenvalue } & 2.401 & 2.917 & \multicolumn{3}{|c|}{ Critical value $=1$} \\
\hline
\end{tabular}

\section{The results}

As explained earlier, the proposed study of this paper uses different statistical tests to examine the hypotheses of this survey. Table 2 summarizes the findings of our survey.

Table 2

The results of statistical observations

\begin{tabular}{|c|c|c|c|c|c|c|c|c|c|}
\hline \multirow{2}{*}{ Exogenous } & \multirow{2}{*}{ Endogenous } & \multirow{2}{*}{ Value } & \multirow{2}{*}{ Standard error } & \multirow{2}{*}{$\mathrm{t}$} & \multirow{2}{*}{$\mathrm{P}$} & \multicolumn{4}{|c|}{$\mathrm{R}^{2}$} \\
\hline & & & & & & $\mathrm{R}^{2}$ & F & $\mathrm{P}$ & Variable's $\mathrm{R}^{2}$ \\
\hline Monthly income & \multirow{3}{*}{ SWB } & 0.181 & 0.059 & 3.086 & 0.002 & \multirow{3}{*}{0.144} & \multirow{3}{*}{13.999} & \multirow{3}{*}{0.000} & 0.036 \\
\hline Family relationship & & 0.190 & 0.060 & 3.189 & 0.002 & & & & 0.047 \\
\hline Physical health & & 0.229 & 0.060 & 3.846 & 0.000 & & & & 0.061 \\
\hline Monthly income & \multirow{3}{*}{ SWLS } & 0.181 & 0.057 & 3.150 & 0.002 & \multirow{3}{*}{0.182} & \multirow{3}{*}{18.523} & \multirow{3}{*}{0.000} & 0.036 \\
\hline Family relationship & & 0.252 & 0.058 & 4.322 & 0.000 & & & & 0.078 \\
\hline Physical health & & 0.236 & 0.058 & 4.054 & 0.000 & & & & 0.068 \\
\hline Monthly income & \multirow{3}{*}{ Happiness } & 0.202 & 0.057 & 3.565 & 0.000 & \multirow{3}{*}{0.205} & \multirow{3}{*}{21.468} & \multirow{3}{*}{0.000} & 0.045 \\
\hline Family relationship & & 0.252 & 0.058 & 4.382 & 0.000 & & & & 0.079 \\
\hline Physical health & & 0.260 & 0.057 & 4.527 & 0.000 & & & & 0.081 \\
\hline
\end{tabular}

As we can observe from the results of Table 2, there is a positive and meaningful relationship between subjective happiness as endogenous variable and exogenous components including monthly income, family relationship and physical health. In addition, there is a positive and meaningful relationship between life satisfaction and the same exogenous components and the same relationships hold between happiness and exogenous components. The summary of our findings are shown in Fig. 1. and Fig. 2. 


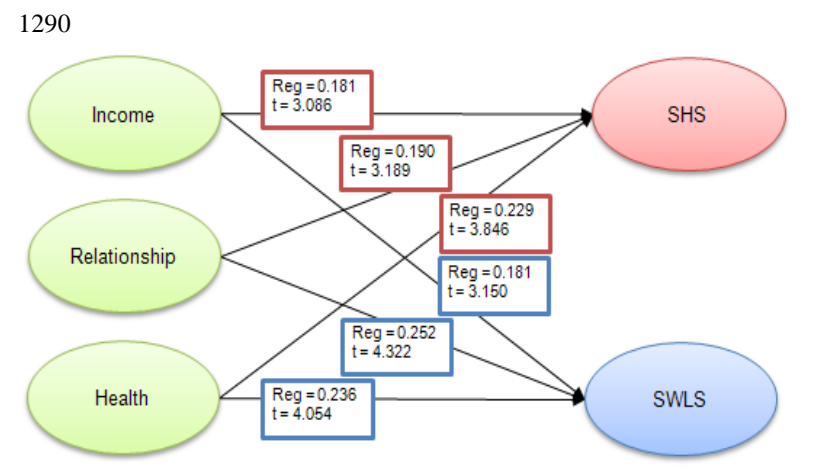

Fig. 1. The relationship between exogenous components and subjective happiness scale (SHS) and satisfaction with life scale (SWLS)

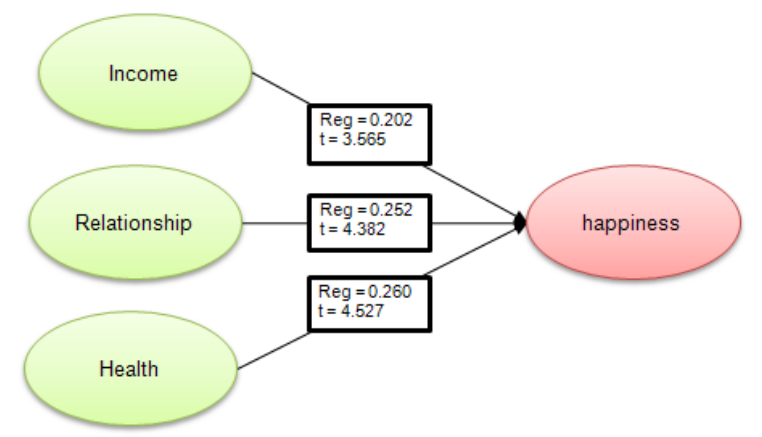

Fig. 2. The relationship between exogenous components and happiness

\section{Conclusion}

In this paper, we have presented an empirical investigation to study the relationship between three exogenous variables including family income, family relationship and health conditions with subjective happiness scale, satisfaction with life scale and happiness. The results have confirmed that family income influences positively on subjective happiness scale as well as satisfaction with life scale. In addition, the results of our survey have confirmed that family income, family relationships and health condition all impact happiness, positively.

\section{References}

Blanchflower, D. G., \& Oswald, A. J. (2004). Well-being over time in Britain and the USA. Journal of Public Economics, 88(7), 1359-1386.

Bruni, L. (2004). The 'Happiness transformation problem'in the Cambridge tradition. The European Journal of the History of Economic Thought, 11(3), 433-451.

Di Tella, R., \& MacCulloch, R. (2006). Europe vs America: Institutional hysteresis in a simple normative model. Journal of Public Economics, 90(12), 2161-2186.

Graham, C. (2008). Happiness and health: Lessons-and questions-for public policy. Health Affairs, 27(1), 72-87.

Kafetsios, K. (2006). Social support and well-being in contemporary Greek society: Examination of multiple indicators at different levels of analysis. Social indicators research, 76(1), 127-145.

Kahneman, D., \& Deaton, A. (2010). High income improves evaluation of life but not emotional well-being. Proceedings of the National Academy of Sciences,107(38), 16489-16493.

Lyubomirsky, S., \& Lepper, H. S. (1999). A measure of subjective happiness: Preliminary reliability and construct validation. Social indicators research, 46(2), 137-155.

McBride, M. (2010). Money, happiness, and aspirations: An experimental study. Journal of Economic Behavior \& Organization, 74(3), 262-276.

Oshio, T., \& Kobayashi, M. (2010). Income inequality, perceived happiness, and self-rated health: Evidence from nationwide surveys in Japan. Social Science \& Medicine, 70(9), 1358-1366.

Paul, S., \& Guilbert, D. (2013). Income-happiness paradox in Australia: Testing the theories of adaptation and social comparison. Economic Modelling, 30, 900-910.

Pouwels, B., Siegers, J., \& Vlasblom, J. D. (2008). Income, working hours, and happiness. Economics Letters, 99(1), 72-74.

Zelenski, J. M., Murphy, S. A., \& Jenkins, D. A. (2008). The happy-productive worker thesis revisited. Journal of Happiness Studies, 9(4), 521-537. 